\title{
A Case of Isoniazid Intoxication in a Dog
}

\section{Jimin $\mathrm{Oh}^{1}$ \\ Hong-Seok Kim² \\ Ji-Houn Kang ${ }^{3}$ \\ Byeong-Teck Kang ${ }^{1}$ \\ Mhan-Pyo Yang ${ }^{1}$ \\ Hakhyun Kim ${ }^{1, *}$}

'Laboratory of Veterinary Internal Medicine, College of Veterinary Medicine, Chungbuk National University, Cheongju 28644, Korea

'Liebe Animal Medical Center, Seoul 08003, Korea

${ }^{3}$ Western Veterinary Medical Center, Seoul 04101, Korea

*Correspondence: kimh@chungbuk.ac.kr

\section{ORCID}

Jimin Oh:

https://orcid.org/0000-0003-1681-6947

Hong-Seok Kim:

https://orcid.org/0000-0001-5126-5672

Ji-Houn Kang:

https://orcid.org/0000-0001-8536-3027

Byeong-Teck Kang:

https://orcid.org/0000-0002-4471-4342

Mhan-Pyo Yang:

https://orcid.org/0000-0002-8043-0152

Hakhyun Kim:

https://orcid.org/0000-0002-8882-2329

Copyright $\odot$ The Korean Society of Veterinary Clinics
Abstract A seven-month-old castrated male Chihuahua weighing $1.6 \mathrm{~kg}$ presented with generalized tonic-clonic seizure following ingestion of isoniazid. Emergency treatment with three doses of diazepam (total $1.5 \mathrm{mg} / \mathrm{kg}$, intravenous [IV]) and phenobarbital ( $15 \mathrm{mg} / \mathrm{kg} \mathrm{IV}$ ) was administered. The seizure stopped after administration of propofol (constant rate infusion [CRI]; $0.2 \mathrm{mg} / \mathrm{kg} / \mathrm{min}$ ). Blood analyses showed mildly increased serum blood glucose concentration, hyperkalemia, and hyperphosphatemia. On suspicion of isoniazid toxicity, activated charcoal $(1 \mathrm{~g} / \mathrm{kg}$, orally), lipid emulsion (CRl; $9 \mathrm{~mL} / \mathrm{hr}$ ), and pyridoxine hydrochloride (70 mg/kg IV) were added to the treatment regimen. Twelve hours after presentation, the dog showed increased serum liver enzyme activities, serum blood urea nitrogen, and creatinine concentrations indicating hepatic and renal failure. Twenty-two hours after presentation, blood analysis still revealed increased liver enzyme activities, blood urea nitrogen, and creatinine concentrations with low blood glucose concentration. Twenty-six hours after presentation, the dog's vital signs deteriorated and the owner elected for the dog to be euthanized. This is the first report of the clinical course of isoniazid toxicosis in a dog in South Korea. Furthermore, to our best knowledge, this is the first report where secondary multiple organ failure was observed due to isoniazid toxicosis. Clinicians should be aware of the possibility of isoniazid toxicosis in dogs. Rapid initiation of treatment after clinical recognition is warranted in such cases.

Key words antimycobacterials, canine, toxicity, pyridoxine. 


\section{Introduction}

Isoniazid (Isonicotinic acid hydrazide) is an antimycobacterial agent commonly used for the treatment of tuberculosis in humans (13). Human patients with isoniazid overdose may present with hypersensitivity, nausea, vomiting, ataxia, hepatitis, symptoms like characteristic of atropine intoxication, lupus-like syndrome, arthralgia, grand mal seizure, and coma (10). Isoniazid toxicosis occasionally occurs in dogs when they accidentally ingest their owners' tuberculosis medicine (4). Clinical signs associated with isoniazid toxicosis in dogs include central nervous system signs with or without seizure, gastrointestinal signs, hyperthermia, cardiovascular abnormalities, and urogenital abnormalities (15). Pyridoxine (vitamin $\left.B_{6}\right)$, the direct antagonist of isoniazid, can alleviate the clinical signs if administered rapidly. Furthermore, anticonvulsant therapy, fluid therapy, and supportive care are required depending on the clinical signs of isoniazid toxicity. Overall, the prognosis for isoniazid toxicosis ranges from poor to grave because the immediate initiation of treatments, such as pyridoxine administration, is rarely possible.

This report presents the details of a dog with isoniazid ingestion, severe seizures and presumptive secondary multiple organ failure. The pathophysiology of hepatic and renal failure secondary to isoniazid intoxication and presumptive treatments for said conditions are discussed. To our knowledge, this is the first report of isoniazid toxicosis in a dog in South Korea. Thus, the object of the present report is to provide the awareness of isoniazid intoxication to veterinary clinician in South Korea.

\section{Case Report}

A seven-month-old castrated male Chihuahua weighing $1.6 \mathrm{~kg}$ presented with generalized tonic-clonic seizure following ingestion of isoniazid. The dog had no history of any neurologic signs or ill health. The owners reported that the dog had accidentally ingested a drug that included isoniazid, which one of their family members had been taking for the treatment of tuberculosis. Presentation occurred approximately five hours after ingestion. On physical examination, the dog showed tachycardia (heart rate of $>180$ beats per minute), tachypnea (respiratory rate of $>100$ breaths per minute), and hyperthermia (rectal temperature, $40.9^{\circ} \mathrm{C}$ ). No heart murmur or lung adventitious sounds were noted on auscultation; however, pale mucous membrane and prolonged capillary refill time ( $>2 \mathrm{sec}$ ) were detected, but systolic blood pressure was $127 \mathrm{mmHg}$ as measured by Doppler ultrasonic method. During a physical examination, emergency treat- ment with three doses of diazepam (total $1.5 \mathrm{mg} / \mathrm{kg}$, intravenous [IV]; Diazepam inj., Myungin Pharm., Seoul, South Korea) was initiated to stabilize the generalized tonic-clonic seizure; however, the seizure continued. Phenobarbital (Phenotal Inj., Daehan New Pharm Co., Ltd., Hwasung-si, South Korea) was then administered ( $15 \mathrm{mg} / \mathrm{kg} \mathrm{IV})$, followed by a constant rate infusion (CRI) of propofol $(0.2 \mathrm{mg} / \mathrm{kg} / \mathrm{min}$; Anepol inj., Hana Pharm Co., Ltd., Seoul, South Korea). The complete blood counts of the dog were unremarkable. Serum biochemistry profile showed an increased serum blood glucose concentration $(187 \mathrm{mg} / \mathrm{dL}$; reference interval $[\mathrm{RI}]=$ 65-118 mg/dL) with mildly increased alkaline phosphatase (ALP) (164 IU/L; RI = 29-97 IU/L) activity and serum blood urea nitrogen (BUN) concentration (34 mg/dL; Rl = 7-25 mg/ $\mathrm{dL}$ ). Serum C-reactive protein (CRP) concentration was increased as well (30 mg/L; RI $=0-20 \mathrm{mg} / \mathrm{L})$. Abnormalities in serum electrolyte levels included hyperkalemia $(8.6 \mathrm{mmol} / \mathrm{L}$; $\mathrm{RI}=3.6-5.8 \mathrm{mmol} / \mathrm{L})$ and hyperphosphatemia $(14.0 \mathrm{mg} / \mathrm{dL}$; $\mathrm{RI}=2.6-6.2 \mathrm{mg} / \mathrm{dL}$ ) (Table 1). Administration of $0.5 \mathrm{unit} / \mathrm{kg}$

Table 1. Sequential serum biochemical and electrolytes values of a dog with isoniazid-induced seizure with hepatic and renal failure

\begin{tabular}{|c|c|c|c|c|}
\hline Parameters & $\begin{array}{c}\text { At pre- } \\
\text { senta- } \\
\text { tion }\end{array}$ & $\begin{array}{l}12 \text { hours } \\
\text { after }\end{array}$ & $\begin{array}{c}22 \text { hours } \\
\text { after }\end{array}$ & $\begin{array}{c}\text { Reference } \\
\text { intervals }\end{array}$ \\
\hline Total protein & 5.4 & 3.6 & 2.9 & $5.4-7.1 \mathrm{~g} / \mathrm{dL}$ \\
\hline Albumin & 3.5 & 2.4 & 1.4 & $2.6-3.3 \mathrm{~g} / \mathrm{dL}$ \\
\hline Globulin & 1.9 & 1.2 & 1.5 & $2.7-4.4 \mathrm{~g} / \mathrm{dL}$ \\
\hline AST & ND & 2378 & 2011 & $23-66 \mathrm{IU} / \mathrm{L}$ \\
\hline ALT & 98 & 1658 & 1251 & 21-102 IU/L \\
\hline GGT & ND & 37 & 28 & $1-10 \mathrm{IU} / \mathrm{L}$ \\
\hline ALP & 164 & 263 & 1353 & 29-97 IU/L \\
\hline Bile acid & ND & $>250$ & $>250$ & $0-25 \mu \mathrm{mol} / \mathrm{L}$ \\
\hline BUN & 34 & 49.7 & 63.5 & $7-25 \mathrm{mg} / \mathrm{dL}$ \\
\hline Creatinine & 1.1 & 1.6 & 2.7 & $0.5-1.5 \mathrm{mg} / \mathrm{dL}$ \\
\hline Glucose & 187 & 136 & 63 & $65-118 \mathrm{mg} / \mathrm{dL}$ \\
\hline CK & ND & 5972 & 5015 & $42-530 \mathrm{IU} / \mathrm{L}$ \\
\hline Lactate & ND & 4.96 & 4.47 & $0.5-2.5 \mathrm{mmol} / \mathrm{L}$ \\
\hline CRP & 30 & ND & 35 & $0-20 \mathrm{mg} / \mathrm{L}$ \\
\hline Sodium & 146 & 146 & 142 & $141-152 \mathrm{mmol} / \mathrm{L}$ \\
\hline Potassium & 8.6 & 4.6 & 5.3 & 3.6-5.8 mmol/L \\
\hline Chloride & 103 & 118 & 119 & $105-115 \mathrm{mmol} / \mathrm{L}$ \\
\hline Phosphorus & 14.0 & 15.8 & 14.4 & $2.6-6.2 \mathrm{mg} / \mathrm{dL}$ \\
\hline $\begin{array}{l}\text { Total calci- } \\
\text { um }\end{array}$ & ND & 7.8 & 6.7 & $9.0-11.3 \mathrm{mg} / \mathrm{dL}$ \\
\hline Magnesium & ND & 2.7 & 3.2 & $1.8-2.4 \mathrm{mg} / \mathrm{dL}$ \\
\hline
\end{tabular}

ALT, alanine aminotransferase; ALP, alkaline phosphatase; AST, aspartate aminotransferase; BUN, blood urea nitrogen; CK, creatinine kinase; CRP, c-reactive protein; GGT, $\gamma$-glutamyl transferase; ND, not determined. 
of regular insulin (Humulin R inj., Eli Lilly and Company, Indianapolis, Indiana, USA) followed by $2 \mathrm{~g}$ of dextrose per unit of regular insulin were initiated to reduce serum potassium concentration due to the concern of serious complications related to hyperkalemia. Additionally, administration of normal saline was also initiated to restore serum potassium concentration along with careful hydration status monitoring. The elevated serum potassium level was then normalized 12 hours after the treatments (Table 1).

While the propofol CRI was being administered, the dog was also administered a subcutaneous injection of maropitant (1 mg/kg; Cerenia ${ }^{\circledR}$, Zoetis, Parsippany-Troy Hills, New Jersey, USA), followed by $1 \mathrm{~g} / \mathrm{kg}$ of activated charcoal through a nasogastric tube to minimize the absorption of isoniazid from the gastrointestinal tract. During this period, IV fluid with $0.9 \%$ normal saline $(10 \mathrm{~mL} / \mathrm{h})$ and lipid emulsion (CRl; 9 mL/h; Smof Lipid inj. 20\%, Fresenius Kabi, Bad Homburg vor der Höhe, Germany) were administered as well. After four hours of treatments, a cardiopulmonary arrest was unexpectedly occurred during careful patient monitoring. Thus, the administration of propofol was halted and treatment with IV dopamine $(3 \mu \mathrm{g} / \mathrm{kg} / \mathrm{min}$; CRI rate: 1 $\mathrm{mL} / \mathrm{h}$; Huons Dopamine Inj., Huons, Sungnam-si, South Korea) was initiated to restore hypotension (systolic blood pressure $<60 \mathrm{mmHg}$ ) and increase urine production. Furthermore, since spontaneous respiration was lost after cardiopulmonary resuscitation, mechanical ventilation was initiated and mannitol (1 g/kg; Mannitol DHN Infu., Dai Han Pharm Co., Ltd., Seoul, South Korea) was administered intravenously, followed by furosemide (1 mg/kg; Lasix Inj., Handok, Seoul, South Korea). The blood glucose concentration of the dog, which was measured using a handheld glucometer, was below $40 \mathrm{mg} / \mathrm{dL}$. Thus, three IV boluses of $50 \%$ dextrose $(0.5$ $\mathrm{g} / \mathrm{kg}$ ) were administered every six hours. Electrocardiography images showed ST-segment slurring and a tall T-wave, indicating that the dog has myocardial ischemia (Fig. 1). Eight hours after presentation, pyridoxine hydrochloride (Pyridoxine $\mathrm{HCl}$ Inj., Huons, Sungnam-si, South Korea) from a human hospital was administered intravenously at a dose of $70 \mathrm{mg} /$ $\mathrm{kg}$ (8). However, spontaneous respiration did not return even after the pyridoxine hydrochloride was administered and the patient's level of consciousness was 'comatose'.

Serum biochemistry profile was repeated 12 hours after presentation (Table 1). The results showed that the total serum protein, albumin, and globulin concentrations had dropped significantly. However, no melena or bleeding signs were observed on physical examination. The significant findings of the serum biochemistry profile revealed hepatic injury as evidenced by increased aspartate aminotransferase (AST: $2378 \mathrm{IU} / \mathrm{L} ; \mathrm{RI}=23-66 \mathrm{IU} / \mathrm{L}$ ), alanine aminotransferase (ALT: $1658 \mathrm{IU} / \mathrm{L} ; \mathrm{RI}=21-102 \mathrm{IU} / \mathrm{L})$, gamma-glutamyl transferase (GGT: $37 \mathrm{IU} / \mathrm{L} ; \mathrm{RI}=1-10 \mathrm{IU} / \mathrm{L})$, and ALP (263 IU/L; RI = 29$97 \mathrm{IU} / \mathrm{L})$ activities. Additionally, the dog was suspected to have acute kidney injury based on the observation of elevated serum creatinine concentration (1.1 to $1.6 \mathrm{mg} / \mathrm{dL}$ ) (6). The dog also showed markedly increased serum creatinine kinase (CK) concentration (5972 IU/L; RI $=42-530 \mathrm{IU} / \mathrm{L}$ ) and hyperlactatemia $(4.96 \mathrm{mmol} / \mathrm{L} ; \mathrm{Rl}=0.5-2.5 \mathrm{mmol} / \mathrm{L})$. Evaluation of the serum electrolytes revealed hyperphosphatemia (15.8 mg/dL), hypocalcemia (7.8 mg/dL; Rl = 9-11.3 mg/dL), and mild hypermagnesemia $(2.7 \mathrm{mg} / \mathrm{dL} ; \mathrm{RI}=1.8-2.4 \mathrm{mg} /$ $\mathrm{dL}$ ). Thirteen hours after presentation, the dosage of the dopamine CRI was increased to $9 \mu \mathrm{g} / \mathrm{kg} / \mathrm{min}$ and maintained overnight.

Blood analyses were repeated approximately 22 hours after presentation (Table 1). The results showed that the dog's hematocrit was decreased (37.2\%; RI = 37.3-61.7\%). In addition, the total serum protein, albumin, and globulin con-

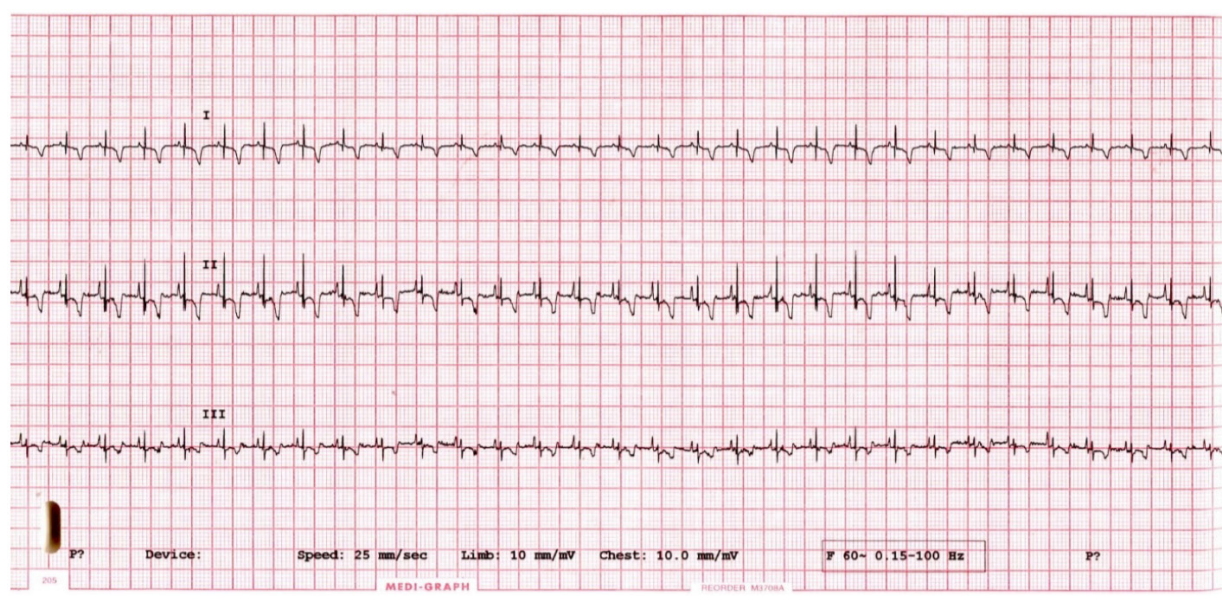

Fig. 1. Results of echocardiography performed five hours after presentation. Lead II shows ST-segment slurring and tall T-wave, indicating that the dog has myocardial ischemia. 
centrations had gradually decreased. The significant results included elevated liver enzyme activities (AST $=2011 \mathrm{IU} / \mathrm{L}$, $\mathrm{ALT}=1251 \mathrm{IU} / \mathrm{L}, \mathrm{GGT}=28 \mathrm{IU} / \mathrm{L}$, and $\mathrm{ALP}=1353 \mathrm{IU} / \mathrm{L})$, and elevated BUN $(63.5 \mathrm{mg} / \mathrm{dL})$ and creatinine $(2.7 \mathrm{mg} / \mathrm{dL})$ concentrations. CK (5015 IU/L), lactate $(4.47 \mathrm{mmol} / \mathrm{L})$, and CRP (35 mg/dL) concentrations were also increased. Assessment of serum electrolytes revealed hyperphosphatemia $(14.4 \mathrm{mg} /$ $\mathrm{dL})$, hypocalcemia $(6.7 \mathrm{mg} / \mathrm{dL})$, and hypermagnesemia (3.2 $\mathrm{mg} / \mathrm{dL}$ ). The concentrations of sodium and potassium ions were within the normal range. Venous blood gas analysis showed a severe metabolic acidosis $([\mathrm{pH}=6.97$; $\mathrm{Rl}=7.31$ 7.46], $\left[\mathrm{P}_{\mathrm{CO}_{2}}=53.1 \mathrm{mmHg} ; \mathrm{RI}=27.0-50.0 \mathrm{mmHg}\right],\left[\mathrm{HCO}_{3}{ }^{-}\right.$ $=11.6 \mathrm{mmol} / \mathrm{L} ; \mathrm{RI}=21-28 \mathrm{mmol} / \mathrm{L}])$, and increased anion gap $(28.0 \mathrm{mmol} / \mathrm{L} ; \mathrm{Rl}=7-16 \mathrm{mmol} / \mathrm{L})$. The dosage of the dopamine CRI was increased to $13 \mu \mathrm{g} / \mathrm{kg} / \mathrm{min}$. Mannitol $(0.5$ $\mathrm{g} / \mathrm{kg}$, IV) was administered, followed by furosemide (1 mg/ $\mathrm{kg}$ ); however, the dog still had no spontaneous respiration. Twenty-six hours after presentation, the dog was euthanized at the owner's request owing to the lack of response to therapy and the poor prognosis of the case.

\section{Discussion}

This report describes a case of acute isoniazid toxicosis in a Chihuahua that presented with a refractory seizure followed by a coma and secondary organ failure.

Isoniazid is one of the anti-tuberculosis drugs commonly used for treatment of tuberculosis in humans. After oral ingestion, isoniazid is absorbed rapidly and reaches its highest blood concentration level within one to two hours (24), with clinical signs observed within 30 to 60 minutes (3). The drug is mostly marketed as $300 \mathrm{mg}$ of isoniazid per tablet. The median lethal dose of isoniazid in dogs is estimated to be 50 $\mathrm{mg} / \mathrm{kg}$ (23). However, considering the findings of a previous study, at least $29.4 \mathrm{mg} / \mathrm{kg}$ of isoniazid can be lethal to dogs (15). In the present case, the dog ingested at least $100 \mathrm{mg} /$ $\mathrm{kg}$ of isoniazid; however, the exact dose of isoniazid the dog ingested was not known.

Acute isoniazid intoxication is associated with the clinical triad of refractory seizures, lactic acidosis, and coma (20) as observed in the present case. Isoniazid forms compounds called isoniazid-pyridoxine hydrazones that competitively inhibit the activity of pyridoxine kinase, resulting in deficient pyridoxine concentration in both tissue and serum (19). These compounds further inhibit the synthesis of $\gamma$-aminobutyric acid (GABA), an inhibitory neurotransmitter in the central nervous system. A decrease in GABA concentration is indubitably the major cause of isoniazid-induced seizures (19). Diazepam, a benzodiazepine, can enhance the binding of GABA to its receptors in neurons and increase the frequency of the opening of the chloride channels of GABA receptors (22). This mechanism of action makes diazepam suitable for anticonvulsant therapy. On the other hand, phenobarbital, which is a barbiturate, induces anticonvulsant effects by increasing the duration of the opening of chloride channels (22). Since synthesis of GABA is suppressed in isoniazid toxicosis, the anticonvulsant actions of diazepam or phenobarbital may not be effective as shown in the present case, or a higher than conventional dose may be required for this type of seizure (3).

As a direct antagonist of isoniazid, pyridoxine could reverse the clinical signs of isoniazid toxicity (15). Isoniazid combines with pyridoxine directly, forming an inactive complex and that is then excreted in urine (14). Therefore, it has been considered that the prognosis for isoniazid toxicity would be fair if pyridoxine can be administered quickly. As an antidote for isoniazid toxicosis, pyridoxine has dose-related effectiveness against seizure and death (3). The recommended IV dose of pyridoxine is the equivalent of the dose of isoniazid that was ingested, i.e., the pyridoxine to isoniazid dose ratio is 1:1 $\mathrm{mg}$ for $\mathrm{mg}$ (16). If the dose of ingested isoniazid is unknown as in the present case, the recommended dose of pyridoxine that should be administered is $70 \mathrm{mg} / \mathrm{kg}$ (8). Thus, the dog in the present case was administered $70 \mathrm{mg} / \mathrm{kg}$ IV of pyridoxine eight hours after presentation. Owing to lack of stock in the clinic, pyridoxine could not be administered immediately; thus, the clinical signs did not improve. However, in one study of human isoniazid overdose, administration of additional pyridoxine after the seizure stopped reversed the prolonged obtundation (1). It has been identified that dogs genetically lack N-acetyltransferase (NAT) 2, which is an enzyme metabolizes isoniazid (21). Considering that dogs are slow acetylators (lack of NAT2 activity) and have low capacity to metabolize isoniazid, the severity and duration of toxicosis they experience might be worse than that experienced by fast acetylators such as humans. Thus, there is possibility that the dose of pyridoxine may have been insufficient to detoxify the ingested isoniazid and that additional administration of pyridoxine might have been necessary.

There are previous reports regarding isoniazid toxicosis in dogs $(2,4,15)$, but secondary multiple organ failure, especially concurrent hepatic and renal failure, has not been reported previously. As described in the present case, secondary organ failure, such as hepatic and renal failure, as a result of rapid absorption of isoniazid can make the prognosis of isoniazid toxicity poor. Hepatotoxicity is one of the well-known side effects of isoniazid therapy. Isoniazid is metabolized mainly in the liver through hydrolysis, cytochrome P450-dependent oxidation, and NAT activity. In the metabolic pathway of iso- 
niazid, the enzyme NAT2 is responsible for the metabolism of isoniazid to acetyl-isoniazid and further acetylation of acetyl-hydrazine to diacetyl-hydrazine (17). Among these metabolites, acetyl-isoniazid and diacetyl-hydrazine are less toxic; however, acetyl-hydrazine can cause hepatocellular damage through hepatocyte vacuolation and glutathione depletion (11). Since dogs genetically lack NAT2 and are considered slow acetylators, the elimination half-life of isoniazid in dogs is two to five hours, which is longer than the one to two hours for fast acetylators such as humans (21). Moreover, a recent study proposed that isoniazid creates covalent bonds with liver proteins, leading to immune-mediated hepatic injury (9). Therefore, acute hepatic failure can occur in dogs after isoniazid ingestion as described herein.

The mechanism of acute renal failure in the present case can be somewhat complex, and could not be solely caused by isoniazid intoxication as additional blood chemical analyses were performed after the patient's cardiac arrest. A decrease in effective circulating blood volume caused by cardiac arrest leads to decline renal perfusion, which can result in acute kidney injury as described in the present case. Furthermore, rhabdomyolysis may cause tubular obstruction with myoglobin casts, contributing to decreased renal blood flow and glomerular filtration rate (5). As a result, acute renal tubular necrosis and further oliguric renal failure can occur, making the prognosis poor if therapeutic attempts are not initiated rapidly (4). Urine output was not identified in the present case, and the rapid increase in BUN and creatinine concentrations within 12 hours after presentation indicated acute renal failure. Additionally, about two hours of refractory seizure would cause secondary rhabdomyolysis with marked elevation of CK concentration (18), which can induce additional renal injury. Thus, acute renal tubular injury and rhabdomyolysis caused by a complex mechanism including cardiac arrest and isoniazid intoxication probably contributed to the acute renal failure in the present case.

In the present case, serum albumin concentration suddenly declined. The occurrence of hypoalbuminemia was previously identified in a dog with acute renal failure after isoniazid ingestion (4). The exact cause of hypoalbuminemia in the dog has not been clarified, but there are some possible explanations about the occurrence of hypoalbuminemia based on hepatic failure. One previous study noted that 6 of 11 dogs showing normal albumin concentration at admission developed hypoalbuminemia during hospitalization due to gastrointestinal bleeding, hemoabdomen, cutaneous petechiation and occult internal hemorrhages in various organs including the liver (7). Additionally, hepatic production of albumin might be impaired. In the present case, there was no evidence of obvious bleeding, and the hematocrit was reduced 12 hours after presentation. Although some ranges in hematocrit and serum albumin concentration could be also affected by fluid administration, hypoalbuminemia was progressive.

Regardless of the cause of hypoalbuminemia in dogs with acute hepatic failure, surviving dogs were more likely to maintain normal albumin concentration after treatment (7). Therefore, serial monitoring of serum albumin can be critical in dogs with isoniazid toxicosis. Potential glomerulonephropathy is also considered as a cause of hypoalbuminemia in the present case along with the elevation of BUN (12). However, the cause could not be elucidated because the owner denied renal biopsy and necropsy. Therefore, a study using histopathologic or necropsy findings will be necessary to clarifying the cause of hypoalbuminemia in dogs with isoniazid intoxication.

\section{Conclusions}

Accidental ingestion of isoniazid may occur in companion dogs. Although isoniazid may not be a common toxicant ingested by dogs, the rising incidence of tuberculosis in the human population could exacerbate this. Therefore, clinicians should be aware of its toxicosis as it can induce life-threatening refractory seizures and hepatic and renal failure. After clinical recognition, rapid treatment should be initiated before the occurrence of secondary organ failure.

\section{Acknowledgements}

The authors would like to thank the owner of the dog included in this report. This work was supported by the National Research Foundation of Korea (NRF) grant funded by the Korea government (MSIT) (No. NRF-2021R1F1A1061799).

\section{Conflicts of Interest}

The authors have no conflicting interests.

\section{References}

\footnotetext{
1. Brent J, Vo N, Kulig K, Rumack BH. Reversal of prolonged isoniazid-induced coma by pyridoxine. Arch Intern Med 1990; 150: 1751-1753.

2. Chin L, Sievers ML, Herrier RN, Picchioni AL. Convulsions as the etiology of lactic acidosis in acute isoniazid toxicity in dogs. Toxicol Appl Pharmacol 1979; 49: 377-384

3. Chin L, Sievers ML, Laird HE, Herrier RN, Picchioni AL. Evaluation
} 
of diazepam and pyridoxine as antidotes to isoniazid intoxication in rats and dogs. Toxicol Appl Pharmacol 1978; 45: 713-722.

4. Haburjak JJ, Spangler WL. Isoniazid-induced seizures with secondary rhabdomyolysis and associated acute renal failure in a dog. J Small Anim Pract 2002; 43: 182-186.

5. Heyman SN, Rosen S, Fuchs S, Epstein FH, Brezis M. Myoglobinuric acute renal failure in the rat: a role for medullary hypoperfusion, hypoxia, and tubular obstruction. J Am Soc Nephrol 1996; 7: 1066-1074.

6. International Renal Interest Society. IRIS Guideline recommendations for grading of AKI in dogs and cats. Available at: http:// iris-kidney.com/guidelines/grading.html. Accessed Jul 28, 2021.

7. Lester C, Cooper J, Peters RM, Webster CR. Retrospective evaluation of acute liver failure in dogs (1995-2012): 49 cases. J Vet Emerg Crit Care (San Antonio) 2016; 26: 559-567.

8. Lheureux P, Penaloza A, Gris M. Pyridoxine in clinical toxicology: a review. Eur J Emerg Med 2005; 12: 78-85.

9. Metushi IG, Sanders C; Acute Liver Study Group, Lee WM, Uetrecht J. Detection of anti-isoniazid and anti-cytochrome P450 antibodies in patients with isoniazid-induced liver failure. Hepatology 2014; 59: 1084-1093.

10. Mohanasundaram N, Sekhar T. Computational studies of molecular targets regarding the adverse effects of isoniazid drug for tuberculosis. Curr Pharmacogen Personal Med 2018; 16: 210-218.

11. Preziosi P. Isoniazid: metabolic aspects and toxicological correlates. Curr Drug Metab 2007; 8: 839-851.

12. Ross L. Acute kidney injury in dogs and cats. Vet Clin North Am Small Anim Pract 2011; 41: 1-14.

13. Rubin B, Burke JC. Further observations on the pharmacology of isoniazid. Am Rev Tuberc 1953; 67: 644-651.

14. Sah PPT. Nicotinyl and isonicotinyl hydrazones of pyridoxal. J Am
Chem Soc 1954; 76: 300-304.

15. Schmid DR, Lee JA, Wismer TA, Diniz PPVP, Murtaugh RJ. Isoniazid toxicosis in dogs: 137 cases (2004-2014). J Am Vet Med Assoc 2017; 251: 689-695.

16. Sievers ML, Herrier RN. Treatment of acute isoniazid toxicity. Am J Hosp Pharm 1975; 32: 202-206

17. Singla N, Gupta D, Birbian N, Singh J. Association of NAT2, GST and CYP2E1 polymorphisms and anti-tuberculosis drug-induced hepatotoxicity. Tuberculosis (Edinb) 2014; 94: 293-298.

18. Spangler WL, Muggli FM. Seizure-induced rhabdomyolysis accompanied by acute renal failure in a dog. J Am Vet Med Assoc 1978; 172: 1190-1194.

19. Temmerman W, Dhondt A, Vandewoude K. Acute isoniazid intoxication: seizures, acidosis and coma. Acta Clin Belg 1999; 54: 211 216.

20. Topcu I, Yentur EA, Kefi A, Ekici NZ, Sakarya M. Seizures, metabolic acidosis and coma resulting from acute isoniazid intoxication. Anaesth Intensive Care 2005; 33: 518-520.

21. Trepanier LA, Ray K, Winand NJ, Spielberg SP, Cribb AE. Cytosolic arylamine $\mathrm{N}$-acetyltransferase (NAT) deficiency in the dog and other canids due to an absence of NAT genes. Biochem Pharmacol 1997; 54: 73-80.

22. Twyman RE, Rogers CJ, Macdonald RL. Differential regulation of gamma-aminobutyric acid receptor channels by diazepam and phenobarbital. Ann Neurol 1989; 25: 213-220.

23. Villar D, Knight MK, Holding J, Barret GH, Buck WB. Treatment of acute isoniazid overdose in dogs. Vet Hum Toxicol 1995; 37: 473477.

24. Weber WW, Hein DW. Clinical pharmacokinetics of isoniazid. Clin Pharmacokinet 1979; 4: 401-422. 